Christian MORARU

University of North Carolina, Greensboro

c_moraru@uncg.edu

\title{
OBJECTHOOD, FLAT FORM, POLITICAL FORMALISM: OOO AND BEN LERNER'S HATRED OF POETRY
}

Oh, chatty things! They pester you

With steady whispers in your ear, Bronze, velvet, wood, or silk - you hear Them talk to you like people do.

You think they're dead, yet they live too Scattered both far and near Oh, chatty things! They pester you With steady whispers in your ear.

Stories galore - true and untrue Those hermits tell you and appear

To tempt or torment you, anew, With your soul's snows of yesteryear.

Oh, chatty things! They pester you. - Alexandru Macedonski, “The Rondel of Things"1

Always think of the objects. - Ben Lerner, Leaving the Atocha Station

Recommended Citation: Moraru, Christian. "Objecthood, Flat Form, Political Formalism: $\mathrm{OOO}$ and Ben Lerner's Hatred of Poetry." Metacritic Journal for Comparative Studies and Theory 7.1 (2021):

https://doi.org/10.24193/mjcst.2021.11.02

${ }^{1}$ This is my stab at translating Macedonski's poem. The original Romanian title of the work is "Rondelul lucrurilor." 
Abstract: This is a largely theoretical essay that, in conversation with Graham Harman's energetic view of objects and Ben Lerner's idiosyncratic theory of poetry, articulates the basic tenets of a "flat aesthetics" and then moves on to tease out this aesthetics' ramifications in terms of form, reading thereof, and politics. When the object's ontological dignity is acknowledged, as flat ontology does, and further, when literature too is dealt with as an object whose "intransitive" objecthood is recognized, literary form, Moraru argues, no longer reflects an elsewhere, a beyond, or other transcendent place, meaning, or design. Instead, this form deflects clarifying light "prismatically," illuminating other objects, the bigger ensembles into which they are arranged, as well as the potential for new arrangements and worlds. Drawing from Lerner's Hatred of Poetry, the article's closing segment explains how this potentiality is already embedded in form qua object and sprouts dialectically from the limits within which literary forms inherently coalesce.

Keywords: Object, Objecthood, New Materialism, Intensity, Flat Form, Flat Aesthetics, Flat Reading, Exchange, Neoliberalism, Political Formalism, Graham Harman, Ben Lerner

Objects, Graham Harman ruminates on a Heideggerian tone, "are sleeping giants holding their forces in reserve, and do not unleash all their energies at once" (Immaterialism 7). Harman also insists, notably, that those energies are released and so, I might add, objects act, manifest themselves, draw attention, and stir other objects - whether humans are around or not (6). This is, it seems to me, business as usual on a planet that has been signalling more and more distressfully that its existence, far from being predicated on ours ontologically, cognitively, and otherwise, may in fact be jeopardized by it. But if this is true, then, pace Harman, Manuel DeLanda, and other advocates of object-oriented ontology (OOO), the notion of an art "autonomous from humans" (Harman, Art and Objects 44) and even of an aesthetic "world without us," while bringing us down a peg, would not be farfetched at all.

Entertaining this largely non-“correlational” hypothesis here ${ }^{2}$, I argue that something like the energy outbursts described by the American philosopher fires up a

\footnotetext{
2 "Correlationism," explains Quentin Meillassoux, the philosopher the term is associated with, "consists in disqualifying the claim that it is possible to consider the realms of subjectivity and objectivity independently of one another." Correlationism contends, the philosopher maintains with a reference to French phenomenologists Philippe Huneman and Estelle Kulich, that "the world is only insofar as it appears to me as world, and the self is only self insofar as it is face to face with the world, that for whom the world discloses itself" (Meillassoux 5).
} 
transhuman, "flat" aesthetics, an aesthetics, that is, premised neither on our presence nor on our proximity and thriving both inside and outside the anthroposphere and its human domains of art production, distribution, and appreciation. 3 I also stress, however, that how we conduct ourselves around objects when these existents or entities discharge their energies matters - how we act on and react to objects qua objects, viz., how we handle their immanence, their objecthood ultimately. But our behavior does not make a difference because what objects fundamentally are, mean, and express hinges a priori on humans' response to them - the anthropocentric presumption of one modern school of thought and criticism after another - or because, as Harman also contends in a similarly Kantian vein, we somehow wind up filling in for objects, courtesy of our unique knack for processing metaphors (Object-Oriented Ontology 72, 83, 85). Obviously, a molehill or painting does appear in a certain way to us, or ways, rather, depending on circumstances, on who "us" is, and so forth. The point, though, is that molehills do not morph into mountains in the absence of a human onlooker, nor does Francisco Goya's The Third of May 1808 quit being the artwork it had been before our visit to the Prado and, regardless of what we might "experience" there, will continue to be after that. Our object-related comportment counts because it calibrates our capacity to relate to objects and their meanings aesthetically so that we ourselves, and for our own sake, awaken into aesthetic experience as rocks, astrolabes, snippets of speech, and novellas wake up from their slumber. Myriad of such entities have been there all along, sometimes fully and other times holding back, throbbing in the mode of an idle ontology of sorts and yet no less involved for that in the making and remaking of various animate and inanimate Latourian assemblages. As I show, a certain politics characterizes the setting up and overhauling of these ensembles. This is an objectual politics riding on the effectiveness with which objects resist transcendence and assert their opaque form, their objecthood. Ben Lerner's work and especially his theory of poetry, to which I turn in last part of this intervention, help us see that, in its very limitation and "imperfection" as a formal object, literature opens up - inside rather than outside itself - a potentiality, a space where change can be envisioned.

3 The "flat aesthetics" phrase has been in use occasionally and especially in OOO-influenced art theory. For example, in her article "An Aesthetic of Everything Else: Craft and Flat Ontologies," Barbara Wisnoski works off New Materialism, with particular reference to Harman and "flat ontology," to "show how flattened aesthetic frameworks, what I call flat aesthetics, recognize the ordinary experience of making [i. e., craft] in relational terms, as part of a dynamic network of agential forces" (205). Rhett Russo also uses the expression in an essay titled "Architecture, Deep and Cryptic" (277). 


\section{Flat Aesthetics}

Trees forever falling in the world's forests, objects have been - and have been active and even active aesthetically - while or without being contemplated and perchance "enjoyed" by Harman's human "beholder" (Harman, Art and Objects 9). 4 There are moments, however - "kairotic" milestones in the course of their lives - when they become present with a new intensity, as Gilles Deleuze and Félix Guattari would say (A Thousand Plateaus 31-32)5. Powered by it, objects light up ontologically, as it were, and by the same token aesthetically. When that happens, their presence swings into hyperpresence, into an intense presence we may feel and are actually called on to take in and answer as soon as we cross into their energy field. Energetic in a heightened but self-collected and understated kind of way, intensive or hyperpresent entities need not change visibly nor move physically in order to move us. If we are there when objects let their energies loose with escalated force, and if we are not impervious to the event, for an event it is, we may get the impression that objects turn to face us; they have been facing the world, but now we may sense that they are facing us. As Harman comments with a direct reference to Michael Fried's 1967 influential essay Art and Objecthood and obliquely to Emmanuel Levinas, we are confronted then by objects' "facingness," and so we too are facing their faces (Harman, Art and Objects 75). Quite ad litteram in that regard, they become our con-cern, visually and in many other ways. And, if their hyperpresence truly concerns us - if we genuinely pay attention to it - then we ourselves face and must face up to what makes that hyperpresence hyperpresent, namely, its particular material texture or form.

No doubt, this is a challenge. For the hyperpresent object typically animating flat aesthetics hardens into a materiality even more difficult to sidestep sensorially and transcend interpretively than before, an objectuality that advertises its self-indexing opaqueness as well as its position, its being-there - or being-here, rather, acutely, immediately present - in the bigger ensemble the object in question is part and parcel of. The same power spike that triggered the object's rise into a thing impossible to explain away, rationalize, instrumentalize, and substitute with "clarifying" meaning, "depth," "worth," and other values assigned hermeneutically - ideologically, politically, morally, commercially, and in other regimes of analysis and assessment -

\footnotetext{
4 "[B]eholders," Harman asserts confidently, "are needed for art just as carbon is required to form an organic chemical" (Art and Objects 174).

5 Intensity is, of course, a pivotal concept in the two thinkers, particularly in Deleuze and especially in chapter 5, "Asymmetrical Synthesis and the Sensible," of his 1968 Difference and Repetition (293-343).
} 
brightens up the circuitry to which the object belongs, making other objects and, in some cases, the entire objectual motherboard more visible or perhaps discernable for the first time. In fact, the system's newly acquired brightness and what this salience affords us existentially, aesthetically, or cognitively flow from the higher intensity with which the system component, the object, exists, or insists, rather, from its quiet insistence to be and to be what it is instead of what it putatively is a representation, effect, designation, or conduit of. These affordances follow from the wordlessly eloquent resolution with which the object stops short of fulfilling a predetermined function and vanishing in its exercise by standing in for an objective outside the object, for an elsewhere, a beyond, a critical conjecture, a convenient "alternative," or other human projection. The object's raison d'être is not to "channel" anything other than itself. The object still means, and so does its system. But meaning here is also a function of the object's being-here, of its presence, so what objects and their energies and networks signify and spark - good or bad, beautiful or less so - does not preexist, nor does it take place outside the object and the other objects it may be associated with.

Still shaped by, and bearing witness to, emotions, history, and politics, the object does remain "constructed" by them, as it also stands oriented - and thus poised to affect other objects - affectively, historically, and politically; it stems from a palpable world and has no less palpable effects ${ }^{6}$. The object declines, however, as Harman would put it, to be "literalized" by design, use, and interpretation into their affective, historical, and political accessory, to exist or rather subsist extraneously as their mere epiphenomenon, index, or implement. In this respect, flat aesthetics is not one of subsistence but insistence, of objects insisting in a revved-up, high-density, and uncircumventable presence. Unlike Harman, I think that while endeavors to "literalize" them do threaten to "replace" them by "disappearing" their objecthood into this or that uptake or "explanation" (Art and Objects 69), they do not "withdraw" by hiding their "reality" in the world's chiaroscuro (Harman, Object-Oriented Ontology 38). To the contrary, Martin Heidegger's hammer, St. Elmo's fires, and scratch-off lottery tickets step forward and show themselves with more aplomb as they "fail," with characteristic composure and, not infrequently, mute deliberation, to do their job selfeffacingly, "transparently" as tools, clues, symptoms, and other vehicles, metaphorical or not, for concealed or remote tenors, rationales, and ends.

\footnotetext{
${ }^{6}$ On the compatibility of "construction" and the recalibration of the critique project, see Iovănel.
} 
Thus, at the same time that they withstand their substitution, erasure, and skirting around through "literalization" as Harman and others view it, objects' vivaciousness of presentation, the hyperpresentation that makes them be and brings out their being energetically, forgoes Harman's metaphorics, whose brief is to reach behind the object's sensuous veil and "give us" the "thing in its own right" (86). An interesting role reversal takes place at this point: on one side, hyperpresence affirms the sensual object non-metaphorically, with an impetus bordering on the literal insofar as there are no two ways about the object's "hereness," but this upsurging force or energy is not limited nor limits the object to one, denotative mode of being and meaning; on the other side, if Harman's metaphorical protocols are tasked with getting past the object's concrete "hereness" to retrieve "the infamous thing-in-itself," then they risk enacting just another kind of Harmanian literalization (Harman, ObjectOriented Ontology 86). Not that the "thing-in-itself" exists, as Harman and others allege repeatedly. But if it did, it would already "be there" - or, as I prefer to say, "here" - and thereby appear sensorially, in and via its appearance or form itself, wherein the Heideggerian ontological difference would collapse, and so would that between the ontic object one touches and Harman's "real," absconded object (Harman, Art and Objects 98). "Welded inextricably to what things are," appearance is, as Timothy Morton emphasizes, inseparable from their essence ("Use the Force" 77). In reality, he quickly corrects himself, the two are more than "welded," for "[a]ppearance and essence are like two different 'sides' of a Möbius strip, which are also the 'same' side" (77).

This side, the only there is, is the side of the thing's presentation, where the thing, rather than receding, at once is and appears. "Appearance" should then not be understood here as impression, let alone semblance or false front, which does not mean that whatever appears is or means exactly what it seems ("appears" to be or mean) either, hence the persisting import of careful examination, interpretation, and criticism, as we will see before long. In appearing, the "thing in itself" shows itself in and is one with the object as inescapably less-than-perfect form, more to the point, with the object's form as this form itself performs, at the zenith of an inevitably imperfect performance of its essence and of sometimes "tactical" dysfunctionality - at the very moment of its misfiring as form, vehicle, message, or expression. Otherwise put, whether in its inexorably formal and therefore formally constrained ability to achieve an "essence" (idea, meaning, design, intent) or in its calculated refusal to 
embody a reality, context, causality, and concept beyond or in lieu of itself, this very form can be said to be, faute de mieux, "the infamous thing-in-itself." Once more, no metaphor and, more broadly, no "meta" either, no transcendental élan invigorate or "disclose" this thing's noumenal thingness, unless the meta is that of metonymy, not of metaphor - of the metonymic or, as I also echo Harman below, paratactic logic that has the individual object's crisis flagging the systemic troubles of the bigger ensemble.

A kind of semiotic and cultural thermodynamics drama unfolds here, a script of meaning, social reference, and the multiple forces and investments galvanizing them, where the whole action flows out from the entity or object's ontological vibration, from an existential insistence solidified into form. I call that form flat and intransitive, which, admittedly, is partly redundant. To clarify, flat form points to flat aesthetics and, through it, to better-known flat ontology. Therefore, this form's flatness conveys, on one hand, the aspirational if not effectively non- or post-anthropocentric democracy of aesthetic existents generally within an ideally non-hierarchical, "flattened" existential and aesthetic continuum.7 On the other hand, flat form foregrounds the need to revisit our picture of the latter as a domain of objects whose unrevealed "truth" or "subtext" critics all-too-confidently "bring to light" or "plumb" by "breaking through" or "diving" underneath those objects' "shell" or "surface." It is in relation to this second sense of form that flatness - flatness as formal attribute somewhat overlaps with intransitivity. An immediacy rather than an intermediacy, the intransitive object inhibits "drive-through" meaning-making, cavalier reading as transit and bypassing. In other words, this object - this unyielding object qua thing, according to critics from Bill Brown to Stephen R. Yarbrough - resists, "wittingly" or not, attempts at passing through, transcending, or circumventing it (Brown, "Thing Theory" 4). ${ }^{8}$ Such moves, it appears to me, would compromise its objecthood by causing intellectual and affective energy leaks and losses at the object site, through the object, whether critics and other "beholders" strove to "get to the bottom of it" by reaching the object's "profundity," the seat of and topological analogy to a "profound" comprehension of the object, or they pushed beyond it, detoured around it through its contextual hinterlands, and so on.

But not only does intransitive form safeguard the object's evaluativeinterpretive impermeability; it also maintains intensity levels within the wider

\footnotetext{
7 I use the term "democracy" as Levi R. Bryant does in his 2011 book The Democracy of Objects.

8 Brown's "Thing Theory" became chapter one in A Sense of Things (21-50). Also see Yarbrough 29.
} 
assemblage, redirects investigative efforts - the common perceiver's or the critic's own cognitive energies - away from the object and toward the system's other existents, warranting their discoverability as system parts one after another and thus elucidating, in all senses, the systematicity of the system. Steven Shaviro has postulated that "[y]ou can never directly confront the network, stare it straight in the eye. For it is always somewhere else from wherever you may be looking" (Connected 5). This is true, but I believe the reverse is also true: wherever you are, you can look for the network if not directly at it; it is just that you are never going to see it all at once ("straight") but indirectly, piece by piece - object by object - as your gaze caroms off them one after another instead of going through them into their (or their network's) metaphysical, political, or semiotic elsewhere. An individual object "allures" us (Harman's term) and so draws us to itself, but its "attraction," Shaviro asseverates, carries us "onward" as well (The Universe of Things 54), "tak[ing] us... toward [the] object's vital connectivity with the world (Fure 110)." For flat aesthetics is also dialectical insofar as nontransparent, opaque form, form that refuses to reflect something else deeper than or past itself and thus be exchanged for something external and extraneous to itself, generates and focuses meaningful light metonymically, on other, adjacent or faraway objects in its objectual chain, and at times, in an ontologically and rhetorically cognate fashion, even synecdochally, on the bigger whole these objects are affiliated with. Having dodged hermeneutical maneuvers to turn it into a mirror, a representation medium through which "clarifying" energies ooze out into a transcendent beyond, above, or below, vertically, the object works like a prism that deflects those energies "paratactically" or laterally, toward the neighbouring penumbras and other obscurities, optical or intellectual, of the greater ensemble. 9 In hindsight, the oftentimes remarkable intellectual and aesthetic upshots of this deflection render, as suggested earlier, intransitive form's imperfection tactical and its failure to play its reflective role ambiguous. For, as it turns out, this malfunction of form is routinely a chapter of a larger strategy of spotlighting realities and meanings "surfacial" in their location inside the ensemble yet by no means superficial. There is a profundity to them, but, with an apparent paradox, it lies flat, in plain sight. This quasi depth attests to the ontological, epistemological, and aesthetic dignity of objects neither reducible nor subordinated to a transcendental realm, objects that are thus

9 On parataxis, see Harman, Art and Objects 66. 
significant in and of themselves as well as relata in a latticework of relations within which they are not convertible into or subsumed to each other either. This flat profundity - this profound flatness - is legible.

\section{Flat Reading}

Flat aesthetics demands, therefore, a flat or, as we have been saying of late, "surface" reading. Much like flatness - and much like flatness in "flat ontology" and "flat aesthetics" also - surface is a serviceable if approximate geometrical trope for how flat reading works. At any rate, where "in-depth" reading variously rehearses the old basesuperstructure interpretation scheme and so ends up transgressing and even cancelling out its object in search of the foreordained "determining" context, flat or surface reading reinstates the object as object, as "sticky" form to be read as such. This makes such reading "close" twice, that is, closely focused on the object as form or, more basically, on the object's form, as well as on whatever other objects may find themselves close to the object. But this reading is "distant" also, in that it gets a purchase on objects situated at various distances from that object inside their ampler ensemble. Either way, to flat readers too "context stinks," or at least they are fed up with historicism's excesses (Felski, “Context Stinks!" 573); in flat-reading practice, this object neither participates in nor is annexed and assimilated by this ensemble as a text is in and by its context according to prevailing critical wisdom. For, in all actuality, this ensemble is not a context or superior order to begin with. Or, if it is an order, it is vaster, not higher. Counterintuitively as it may sound, it presents itself as a string or flat configuration of equal-footing components. On this ground and within this ontologically "horizontal" constellation of elements, the object is no longer a symptom, a stand-in, or other fungible item to be traded for a revelation, disclosure, ambition, and other kind of subtextual or contextual knowledge, value, or aim, but an "energetic" wink, enlightening and valuable, at other objectual links in the assemblage's chain. This chain-as-chain - the system's own systematicity or objecthood - is itself on the surface and makes up that surface, a flat entity itself produced metonymically and for that reason discoverable, readable "laterally."

Not unlike the New Critics before him, Harman suspects that all contextualizations, trades, and conversions displace the object, replacing it with an "account of its components or its effects, as literary critics have long known" (Harman, Immaterialism 8; italics mine). We have seen that his suspicions, by my 
lights at least, do not always steer clear of some pitfalls. I do concur, however, with his overall argument, and I also appreciate its added bonus, as he does not just rebuke such misguided "paraphrasing" bids, but he also challenges the same critics to deal with literature in ways owning up to objecthood rather than de facto voiding it through "overmining" and "undermining" analyses that, separately or in some combination, presume to "explain it in terms of its smaller constituents," histories, properties, effects, and the relations it is enmeshed in (Immaterialism 8-11). In throwing down the $\mathrm{OOO}$ gauntlet, he nonetheless dares us to pick it up analytically for, after all, analysis, responding to things descriptively, is not only what critics have long known but also what they have been known to do. Granted, analysis risks "reducing" (7-12) a novel or poem to what it is not and thus exchange it for the generic and not seldom inflated currency of critical interpretations and representations. Such analysis or handling of objects, including linguistic and literary objects, is not, however, the only one imaginable, and thinkers like Harman have been urging us to imagine just that. What he and other proponents of speculative realism have been dwelling on is essentially both the shortcomings and the necessity of commentary and criticism broadly - of a criticism that still does analytical labour and responds to literature but whose response, apposite to the outflow of the literary object's paratactic energies themselves, should be, as I propose, flat, a flat reading.

Making meaning both in agreement and disagreement with some of the tenets of Harman's position, this kind of reading pursues these energizing currents and tensions horizontally, across the object's larger assemblage instead of swapping their objectual source for something else deeper, higher, elsewhere, in another place, form, or medium. This pursuit's modus operandi is constructive rather than deconstructive. It is geared, roughly speaking, to enriching rather than debunking, for, anchored as it is in the object's hereness, this is an investigative routine honed in on expanding and nuancing the world picture the object is a feature of. Flat reading does not seek, or does not seek primarily, to take the ensemble apart and "expose" its "ideological" underbelly, and this is because, more often than not, ideology is and works, along with everything else, "in your face," dispensing with The Matrix-like disguises the likes of Slavoj Žižek so cleverly "uncover." Neither above nor below, ideological and nonideological entities are present, sometimes indisputably, as a matter of evidence and are already on display left and right, hence, again, the laterally inquisitive movements of this reading. Still a critique but quite adept at canvasing and recording a reality 
"degree zero" and its "facts," flat reading has then little interest in reaching over or beneath spaced-out existents, much as it aspires to dismantle neither these objects, individually, nor the configuration they find themselves in. What it seeks instead is largely the opposite, that is, to acknowledge the object-as-object, its objecthood, even - or especially - at a time of crisis and use this reckoning moment as a steppingstone to a vaster recognition, namely, that of the greater objectual configuration. Latching onto a here-world, flat reading activates a novel, analogously immanent analytical regime, one that is not so much dissection, uncovering, transcending, unravelling, and decomposition but compositional and so in many ways comparable to Bruno Latour's “compositionism” (Latour 471-490, mainly 475-485).

This reading regime operates chronotopically, surveying, discovering, and gathering together not only a configuration of hereness, webs and strings of objects juxtaposed spatially, but also this objectual constellation's temporal flipside, to wit, the topography of nowness. Two-pronged, flat reading is then compositional or "comparative" spatially and temporally, comparing present objects in the joint etymological spirit of the Latin comparō ("set next to," "unite") and compāreo ("appear," "be present," "be in existence") and so casting about for the objects' presence and for how they are spatialized or positioned with respect to one another in a particular present. On this account, this reading concurrently measures space and tells time. Better yet, this reading tells time for that space at the very moment it treats and measures that space, "closely" or from a "distance," as spaced-out objects, thus marking out that here-space's now. In reconstituting and composing that objectual arrangement or system, in configuring the form, meaning, and mutual relationships of presences in that assembling space, this reading effectuates, I argue, a reverseengineering of the present as contemporaneity, retracing the production of the contemporary. For the contemporary is neither the present nor a pregiven historical background over and against which existents are and act. The contemporary is a specific configuration of culture, a cultural temporality fostered inside a certain historical temporality or interval in history. Thus, for one thing, the contemporary is not only heterotopic, as it weaves together existents "all over the place," but it may also be and usually is heterochronic, bringing together meaningfully a set of temporally discrepant objects (the latest Corvette model, an original Swiss-made grandfather clock, a dinosaur vertebra); in it, what we are ultimately dealing with is an age of many ages. For another, this is a cultural age, something unique that is produced, something 
that is put together, assembled inside and by that assemblage, by the insistent presence and interplay of objects. If this is the case, then configuring this presence and the panoply of objectual presences constituting it gives us not only the ontological and cultural formula of the present, of the "now" or slice of time we inhabit, but also of the present as con-temporary: as formation, as genesis and defining "structure" of the contemporary as existents relating to one another within the space of a certain composition, arrangement, or ensemble, as well as inside the coevalness or time in which they are with each other inside that space. This objectually orchestrated, materially and culturally shared temporality or co-temporality is the contemporary. Once more, neither a synonym to the historical "now" nor a datum nor an inert backdrop for aesthetic, economic, social, or political figures and their various scripts, the contemporary is but an immanent configuration of human and non-human actors acting on each other, something made by their actions and interactions and whose poiesis is for us to figure out, to read.

This "comparative" making and the obtaining figure or form may betoken, to reiterate, an impasse or incompletion, a wilful or just unavoidable "failure" to deliver and carry off a formal design, whether we talk about the crisis of a single object as form or about the broader parataxis of interrelated objects. The poiesis in question may then also be the chronicle of a fiasco, of an ontological-expressive limitation of the object as form, as well as of a breakdown of objects' defective assembly. But, when they are in play, flaws, incompletion, and whatever the form may be lacking in formally, thematically, and otherwise open up in the object, rather than, again, beyond it, a new and productive space - a space itself poietic, where something novel is brewing. This space is an interstice sheltering a "presence of an absence" as Giorgio Agamben defines "potentiality" in his comments on Aristotle's Metaphysics (Agamben 179). What Harman and other New Materialists say about qualities certainly can be said about two of this form's main traits, namely, imperfection and malfunctionality: neither "exhausts" its ontologically sovereign hereness, its objecthood as form or its formal reality. Quite the opposite, both enhance the object existentially and aesthetically by raising the degree to which it is when it stops being in the transitive modality of a surrogate for or shortcut to elsewhere, to a successfully completed task, to a superior, hidden, or metaphorical order - in brief, when the object "just" presents itself rather than re-presenting or presenting a representation. Coming to the fore, instead of "stepping back," in this auspicious representational crisis, the object's objecthood or 
the object as form accrues Agamben's potentiality only to release it through a burst of intensities that, in their metonymic sweep, reveal or point, rather, to the assemblage of objects, as DeLanda remarks (66-67). In a nutshell, this is what this potential is as an object's feature, or this is what is potential about the object-as-object, about object qua form: neither a transcendental dimension nor a virtuality it may be able to attain in its beyond, but an immanent, in-built ability to "discover" - and thus help us read - left and right, close-by and far-off the rest of the object system.

Since this potential nests inside the object and therefore inside the actual system of objects - inside the system of actuality also known as the contemporary both the object and the system, while flat, as I have emphasized, are only roughly so, in the same way in which, as I have also specified, ontology, aesthetics, and reading are. Yet again, the complexity of texture and semantics need not be imagined as depth and thickness, as deep and thick form. In this sense, the objects populating the storyworlds of contemporary literature and, on another level, this literature itself can be viewed as flat. Nor is this flatness just a misnomer playing fast and loose with geometry. As noted earlier, "flat" also is an ascertainment of intransitive form, of a formal consistency or sui generis formalism. Brought to bear on this "formalist" literary art in terms germane to this art itself, flat reading may be seen as formalist too.

\section{Flat Politics}

If this reading paradigm is the hallmark of a formalism of sorts, that formalism surely a term overburdened by its history - is critical, political even. Emboldening cypher of an otherwise, a futural politics lies embedded, sometimes allusively, sometimes clearly spelled out, in objects taken separately - given that everything issues forth from their uniqueness or form - as well as collectively, in the com-position or paratactic placement, side by side, of the objectual pieces of the contemporary puzzle and, once removed from this system poiesis, in the compositional enterprise of flat reading itself. For this reading sets out not just to rehash analytically the making and makeup of the assemblage so as to work out, à la DeLanda, a system of presence, the structure of that which corrals us into the assemblage and the "historical moment" thus assembled. This reading is also keen on what this present presents but not in its present, in its now - on the embryonic future or what Morton describes as the "not- 
yet-ness built into the ontological structure of a thing" ("Use the Force" 70).10 Flat reading surmises that, much like abovementioned space, this presence too is pregnant with another presence and another present altogether, with another configuration and another time for the objects involved. Both absent "for the time being" and pre-figured in its very absence, this is another time or, better yet, a time for a contemporaneity to come. This time of possible being and largely a time of possibility - a future - flat reading must tell. Writers do so in the first place, and this reading cannot but follow suit.

It should come as no surprise that contemporary American authors dwell persistently on the potentiality of this other to the assemblage and its time by taking on the material and symbolic economy of representation, illustration, and exchange that endanger form through reductions to contents and conversions into values that eschew, degrade, or deform form as form. Preceding modern capitalism, this economy became, inside and outside the economic sphere narrowly understood, a mainstay of modernity in market-oriented no less than in central-planning societies such as those of the former Eastern Bloc type - interestingly enough, possibly more so in the latter, as their 1950s Socialist Realist literature's transparent aesthetics, self-flauntingly ideological representationalism, and aggressive anti-formalism go to show. The postCold War late-global era, however, has taken the transactional logic of modern culture to a whole new level. After 1990, deregulatory neoliberalism marks the onset of paroxysmal exchange in and of a world variously subjected to barter, trade, monetization, and other fungibility protocols keyed to regularizing its singularities into commodifiable series and classifications and translating it into lucrative rationalizations, expedient clichés, and "universally accepted" languages, codes, notions, standards, and liquidity. It is in this already naturalized or "normalized," fastglobalizing geosystem of remunerative transactions that a "new normal" of our exchange condition emerges, according to which things that are, despite their insisting in being so, are unconscionably and obscenely, if profitably, swapped for their ontological double, that is, for what they demonstrably are not: scientific evidence for conspiracy theories, facts for their cockamamie "alternatives," reliable public-domain information for tribal spin, truths for sheer lies, reality for reality TV, planet Earth for

${ }^{10}$ Morton has developed this point previously in the 2012 article "An Object-Oriented Defense of Poetry." 
Trumpland, and the like. ${ }^{11}$ Having flourished across and beyond the so-called social media, the exchange culture rooted in this cynical transactionalism is hardly endemic to the United States, and, as I have observed, predates our juncture in history. But today's America has been front and centre to this culture's proliferation. It is therefore politically heartening to watch U. S. writers of our time taking on this pseudo-reality factory as is aesthetically intriguing to see them doing so on the very terrain of makebelieve and reach, to that end, into the toolbox of fiction writing - of a writing itself flat, which, seemingly with another paradox, presses the fictional into the service of truthfulness and its "hard" and hardly disputable ontologies.

If this category of writing is flat in the existential and aesthetic sense of the term, then so is this writing's politics. Itself flat, this politics befits the objectual being-here, the Harmanian "reality" of the "thing." This thingness has been under siege by forces and in fashions compatible and frequently identical with those driving the broader, economic and political assault on reality by neoliberalism's exchange apparatuses (Harman, Object-Oriented Ontology 38). It is also encouraging to notice that these authors respond in kind to this attack and ensuing transgression, depletion, and cashing out of world reality. For they home in, time and again, on the formally dense, incontrovertible and inconvertible objecthood of objects, more exactly, on those moments in which objects up the ante of their being to make an "energetic" stand as intransitive forms significant and valuable in and of themselves.

\title{
Ben Lerner: Form, Exchange, and the Unexchangeable
}

\author{
... not beauty, but a sublimity of perfect exchangeability ... \\ -Ben Lerner, The Hatred of Poetry \\ ... that banal but supernumerary sublime of exchangeability. To be a subject \\ here was to be spread by objects. \\ -Ben Lerner, The Topeka School
}

Few recent American writers have pushed back against exchange culture more compellingly than Ben Lerner. A leading postmillennial, Lerner stages programmatically, across his whole oeuvre - fiction and nonfiction, poetry and

\footnotetext{
${ }^{11}$ A notable intervention in the discussion of such dyads as fleshed out by recent U. S. fiction and film is Josh Toth's Truth and Metafiction (2021).
} 
criticism - the inexchangeability of objects in general and, in particular, of "metaobjects" such as language and literature ${ }^{12}$. At the intersection of autofiction and metafiction, his work latches onto those entities pivotal to the author's private life and professional livelihood alike - things that have made Lerner who he is: idiom, native and not, its public speaking and "interscholastic-debate" variety, its poetry and prose incarnations, writing in these and other genres, the books and other outcomes such writing may yield, the translations and commentaries it may elicit, and so forth (Lerner, The Topeka School 23). Whether it is the author (speaker, writer) or his or her audience (listener, publisher, agent, reader, critic, translator) who employs language creatively or reactively in reply to what has been penned and said, these are all forms of language use where both form and its use are, and cannot not be, in play simultaneously and inherently bearing on each other. This interlocking of language and its usage, of the idiom's presence, on one side, and on the other, of the spoken and written word's actual or possible transgression or "absencing" through certain kinds of speaking, writing, and reactions thereto, is concomitantly and dialectically Lerner's quandary and the cornerstone of his aesthetic.

The conundrum remains no more than that, namely, an aporetic encumbrance to Lerner's literature and, I would think, to anybody's literature for that matter whenever a casual utterance, public speech, poem, or other linguistic instantiation is simply designed or presumed to relay, express, allegorize, critique, or otherwise represent and by the same token lends itself to decodings, interpretations, translations, and other language maneuverings amounting to a trade-in for messages, ideas, and values extrinsic to form itself. In this exchange regime, use uses up, transiting and thus annulling the "formhood" of form. Because this regime is typical of most literary and non-literary implementations of language, Lerner rejects "utilization" broadly. He does so explicitly in his slim but poignant 2016 manifesto book The Hatred of Poetry, where not only does he rebuff "utilitarianism that is blind

\footnotetext{
${ }^{12}$ David Teh has dealt with "inexchangeable" objects in Jean Baudrillard in "What Is a Sovereign Object? Baudrillard and the Inexchangeable" (2008). Focusing primarily on the French thinker's 1983 Fatal Strategies: Revenge of the Crystal, Teh discusses how Baudrillard's objects defend their "opaque" sovereignty by defying dematerialization through measurements, appraisals, uses, and exchanges. In Teh's account, Baudrillard's crystal is "an object that refuses to surrender to commensurability, that resists overcoding by the commodity. It spells immobility - physical, economic, social and semiotic. It is a model of refraction and reference leading nowhere, just a play of signification where nothing (no value) remains to be signified other than the subject himself, disappearing in his fascination." By contrast, Lerner's objects and the objectual world of contemporary American fiction generally are neither "indifferent" nor "immobile." They do "resist" explanation, calculation, and commodification, but they do so actively and "energetically" via refractions leading, most meaningfully, to other objects.
} 
to everything that can't be instrumentalized," but he also posits that "the use of poetry is therefore entwined with its uselessness" (52). Of course, the antiutilitarian position has been de rigueur among the artists and critics of the post-Romantic era. The "uselessness" claim, though, while also calling up the modernist creed of art for art's sake, is more thought-provoking. Applicable to all literary genres, it has, to Lerner's mind, serious bearings on what writers, $y$ compris himself, do, no less than on what publics of all stripes do with what writers have done and made public - with that for which receivers, distributors, promoters, appraisers, interpreters, translators, historians, and other beneficiaries, intermediaries, and handlers of literature trade literary works in, so to speak, and to which they ultimately reduce them, be that a cognitive-affective value such as an impression, a political message, a theme, a "critique" even, or a commercial value. These are all rationalizing reflexes in a capacious exchange culture susceptible of accommodating, much like capital broadly, a striking range of uses that are not as incompatible with one another as they may seem at first blush. For instance, treating books like commodities, the overtly self-ironic motif of Lerner's 2014 novel 10:04, should be in principle at loggerheads with reading and perhaps also with writing this or any other books as denunciations of commodifying practices. But Lerner hints that, at the end of the day, both commodification and its critique "literalize," as Harman would say, the literary object by "paraphrasing" it financially or critically and thus exchanging it for a "crass" pecuniary equivalent ("a 'strong six-figure' advance," as the narrating protagonist keeps telling us in 10:04) or for a "sophisticated" critical elaboration, respectively (Lerner, 10:04 4, passim.) Either way, an instrumentalization is afoot, expressis verbis in the first case, what with the book being redeemed for a monetary instrument, and figuratively in the second, where the book is valued, or devalued, rather, as a mere conveyor of knowledge "about" it. In the same Harmanian spirit that may rub the wrong way book-trade people as well as critics (Art and Objects 123), the author calls into question both uses of literature, for they both jeopardize the literary object's objecthood by cashing it in actual or cultural currency.

The challenge Lerner mounts to readers and writers, including writers like himself, who grapple with the transactional hazards of representation, no less than to commentators, translators, and others attempting to represent his work and, in a dizzying feedback loop of representation and self-representation, this work's flaunted anxieties about being read and represented, is as strong as, and in fact no different 
from, the provocation Harman addresses to critics and their "analyses." At stake in both authors is the very possibility or, more exactly, the intertwined impossibility and possibility of writing and knowing literature, of literary representation and of critically representing whatever the writer has represented, of the feasibility and infeasibility of reading, of commentary and its vacuity so long as tackling linguistic objects and expressive entities and acts widely occurs in the transactional-transiting regime of use, application, substitution, and other exchange modalities. Lerner's dilemma and aesthetic impasse derive from the dominance of this regime across a cultural environment where literature undergoes incongruous "calculations" as it too is expected to achieve things beyond itself and to be therefore describable, measurable, and worthwhile in terms of that beyond. If poetry is worth something, Lerner maintains, exchange culture does not recognize that value as intrinsically present in the hic and nunc of the literary object as such. Instead, poetry is considered valuable only insofar as it can be assessed - that is, calculated and legitimized heteronomously and thereby subordinated and ultimately boiled down to an au-délà, as the French would say, to a beyond and to something else from another space and time. But, as The Hatred of Poetry expatiates on the genre's hostile reception by lay readers and "so many cultural critics" alike,

[p]oetry is a word for a kind of value no particular poem can realize: the value of persons, the value of a human activity beyond the labor/leisure divide, a value before or beyond price. Thus hating poems can either be a way of negatively expressing poetry as an ideal - a way of expressing our desire to exercise such imaginative capacities, to reconstitute the social world - or it can be a defensive rage against the mere suggestion that another world, another measure of value, is possible. In the latter case, the hatred of poetry is a kind of reaction formation: You lash out against the symbol you are repressing, i.e., creativity, community, a desire for a measure of value that isn't "calculative." "Poetry" becomes a word for an outside that poems cannot bring about, but can make felt, albeit as an absence, albeit through embarrassment. The periodic denunciations of contemporary poetry should therefore be understood as part of the bitter logic of poetry, not as its repudiation (53-54; emphasis mine).

In Lerner, the "logic of poetry" is, to reemphasize, dialectical because as "particular" poems "fail" to re-present, to serve an "outside" and thus accrue a use value they should not be required to carry in the first place, they kit themselves out for a 
presentation that would otherwise remain unpresentable. This presentation does not presuppose use. Or, if it does, this is a "new use." It is actually an offshoot of the "actual poem"'s (74) uselessness, worthlessness, or even misuse - a positive "misuse value" (Brown, "Thing Theory" 2019, 721) accumulating negatively in relation to a cause, politics, social ideal, value system, or other external relevance. ${ }^{13}$ In "failing" to prove themselves "externally," and in failing generally "out there" and by the standards of that out-thereness, "real" poems bounce back on themselves. They "draw" us to them "for "[their] own sake," as Shaviro would comment, "forcing us" to "acknowledge [their] integrity" (The Universe of Things 53), their being-here as a form or whole (see the Latin integrum). In missing the mark of that subservient presentation, they bolster then their own presence, the formally intransitive substance of their hereness so as to open up "internally," much like any other objects, "virtual space[s]" where something beyond the "phenomenal" can be "figured" (75). Plagued or not by patent flaws, "original" or cobbling up rehashed clichés and chunks of pirated works, an existing poem is writing at the limit, a limit in and of itself and so a suspension of "transits" and "uses." As such, the poem flags its own material, formal limitations. By the same movement, however, it gestures to the boundaries of its presence, to the extent of the poem's being-here, the work's equally concrete self-presence circumscribing an ontological area of "not-yet-ness" where being is or can be. Indelibly limited as to what it can do, the poetic object then also de-limits, for it delimitates a space of possibility by making room inside itself for various figurations as well as for all sorts of revealing configurations and for the assemblages these configurations hold together. "Great poets," Lerner avers, "confront the limits of actual poems, tactically defeat or at least suspend that actuality, sometimes quit writing altogether, becoming celebrated for their silence." Further, "truly horrible poets unwittingly provide a glimmer of virtual possibility via the extremity of their failure" while "avant-garde poets hate poems for remaining poems instead of becoming bombs," and "nostalgists hate poems for failing to do what they wrongly, vaguely claim poetry once did" (75-76). Aside from what poets ask of themselves, we call on them "to defeat time, to still it beautifully; to express irreducible individuality in a way that can be recognized socially or, à la Whitman, to achieve universality by being irreducibly social, less a persona than a national technology; to defeat the language and value of existing society; to propound a failure. See Colman's detailed case in his booklet Ben Lerner's 10:04: New Uses for Failure (2018). 
measure of value beyond money" (76). Exchange culture stakeholders like everybody else, poets too face such exigencies and expectations. "Tactically" or not, they come up short whether they make or acquiesce to external demands whose fulfilment is not just unattainable and, indeed, undesirable but which would transcend and thus abrogate the objectual interiority or "flat" depth where another presence, the presence of that which is not there yet, can present itself. But, Lerner insists, the same transactional frenzy that hampers poetry can be "de-perverted" and mobilized in the name of a qualitatively new, aesthetic presentation.

Rekindled in The Hatred of Poetry and returning once more in the 2019 novel The Topeka School, a teenage memory - the primal scene of Lerner's aesthetic project and therefore worth reproducing at some length - dramatizes this tug-of-war of limit and delimitation, impossible goal and possibility, failure and triumph. "[T]he Hypermart [that] opened in Topeka" back in his high-school days," the author reminisces in The Hatred of Poetry,

employed young uniformed workers, uniformed both in the sense of wearing the costume of their franchise but also in the sense of uniformly following the conventions of teenage "beauty" - which was not beauty but a sublimity of perfect exchangeability, the roller skates themselves a gesture, albeit dated, toward capital's lubricity. Every flake or piece of puffed corn belonging to me as good as belonging to you - Warhol is the Whitman of the actual: "A Coke is a Coke and no amount of money can get you a better Coke than the one the bum on the corner is drinking. All the Cokes are the same and all the Cokes are good." The same goodness, the same sameness: The energy that coursed through me, undid me, at Hypermart - a store that was to the snot-nosed me what Mont Blanc was to Shelley - I consider that energy integral to poetry. "Poetry is a kind of money," Wallace Stevens said; like money, it mediates between the individual and the collective, dissolves the former into the latter, or lets the former reform out of the latter only to dissolve again. Do you remember that sense (or have it now) of being a tentative node in a limitless network of goods and flows? Because that's also poetry, albeit in a perverted form, wherein relations between people must appear as things. The affect of abstract exchange, the feeling that everything is fungible - what is its song? The actual song of my early youth might be eighties synthpop, but the impulse that gives rise to it, I maintain, is Poetry (82-83; emphasis mine). 
Notably, the items for sale in the uniformity emporium "undo." That is to say, they disarticulate by serializing the individual purchasing them. In that, they work twice like language, although they do so, admittedly, like a disabling one - recalling the episode in The Topeka School, Adam feels "spread by objects," disintegrated and strewn about to the point of speechlessness by the rhetorical overkill in the reasoning of the opposing debate team (Lerner, The Topeka School 133). Undoubtedly, objects are language, and, vice versa, language is one of them. In an "abstract exchange" regime of equivalence, serialization, and instrumentalization, objects and language alike pull the speaker apart and so ultimately betray their mission, namely, "articulation," the constitution of speech and implicitly of the speaking subject himself or herself. Another, "non-fungible" mode of language, however, a mode in which language is beholden to its own objecthood, may make poetry possible, thus auguring possibility as an ontological principle and with it the hope for a new world, with its own networks, "nodes," limits, and limitlessness. As Lerner points out, the energies that fuel sameness- and equivalence- driven finance, commerce, and consumption are also those setting in motion the self-consuming, singular, and intransitive discourse of poetry; the same "impulses" that disaggregate both language and subjectivity and bring them to a grinding halt help Adam pull himself together as a poet - as Lerner and gear up for the truer "song" inside and the "actual song."

Because it is flat in the sense explicated earlier, this song is and so is both unexchangeable for something else and spacious enough to harbour and prefigure inside rather than outside it what it can be, viz., realms of the feasible, possible, and potential where objectual arrangements and dispensations would not replicate those in the Topeka Hypermart and, more broadly, would not engage pointlessly in replicating, echoing, or re-presenting. Thus, where store language spells out and enforces extant assemblages, poetry presences - anticipates and experiments with descriptions for - others, heretofore absent, much like Agamben's potentiality. Back in Kansas, Lerner relives those anticipations as Adam stumbles on another world, more substantial than the surprisingly immaterial and dematerializing ("abstract") big-box paradise of material goods. That other world is the world of film, drama, poetry, and art largely, a world picture whose potential temporality pushes allegorically from behind against the screen on which the movie of the actual and the "mundane" runs in "clock time" (84-85). "I felt," Lerner recollects Adam's and his various theatre experiences over the years, "that other worlds were possible," a 
"particular alternative world" (84). Nota bene, this is not a particular work, for the "artwork itself" remains limited even when it is "great" (84). But, à la Harman and Heidegger, the "little clearing that theatre makes," the scenic space or hereness Lerner "associate[s] with Poetry," opens up in a play or poem, and into this world one can step provided one experiences, as Harman would also urge, that play or poem as form. Indeed, Lerner confirms, this is an "experience of form" (84), of the linguistic object as form, where experiencing the object does not transcend it but sticks to it, transforming it without using, reducing, or eliminating it, much like somebody's "stutter" intensifies into "song" (85).

If there is a point in calling out poetry's stutter, then there is also a point in Lerner's appreciating the stuttering, stumbling, and want of form on the road to its unrealizable task, for both are crucial to "the dialectic of a vocation no less essential for being impossible" (85). And so what the writer "ask[s] the haters" is to hate more, not less. He wants them to ramp up ("perfect") their disdain for poetry formally by "bringing" their contempt "to bear on poems" until the latter's impenetrable materiality "creat[es]" or, as I prefer to say, uncovers, inside itself and in "the continuous present tense of art," a "place for possibility and present absences (like unheard melodies)," and until scorn itself "might come to resemble love" (85-86). This would be only apt because, as Lerner also ventures, writers themselves rage against the "merely actual" either by inspiring or by displaying "perfect contempt for it," ever in search for the "Poem they cannot write in time" (37) - the "genuine Poem that never appears" (76). The aesthetic of contempt is then, with another "dialectical" reference by Lerner, a via negativa for the authentic (37). Yet again, this aesthetic does not transcend form. Instead, it works on and with form. More exactly, it works through the form's limits - "the finite," the site where form founders - but just to unleash the form or limit's own de-fining, de-limiting "capacity" to "make a new world out of the linguistic material of this one" (37). The new world too is an ensemble of objects, a flat form of surfacial forms available to flat writing and to appositely flat reading. Either first-order (literary) or second-order (readerly), respectively, both enact presentations that do not liquefy or liquidate the work's objecthood, given that their writing and reading modes are neither predicated on nor catering to an external causality or rationale. Doing without any logical, ideological, or ontological crutch, flat form relies "negatively" on its own trite actuality qua form to conjure up the virtual and the 
possible - to reassemble Hypermart-like assemblages into unprecedented ensembles in which new meaning, values, and choices become available.

\section{References:}

Agamben, Giorgio. Potentialities: Collected Essays in Philosophy. Edited and Translated, with an Introduction by Daniel Heller-Roazen. Stanford, CA: Stanford UP, 1999.

Brown, Bill. A Sense of Things: The Object Matter of American Literature. Chicago, IL: The University of Chicago Press, 2003.

---. "Thing Theory.” Critical Inquiry 20, no. 1 (Autumn 2001): 1-22.

---. “Thing Theory.” In The Bloomsbury Handbook of Literary and Cultural Theory, edited by Jeffrey R. Di Leo. London, UK: Bloomsbury, 2019: 720-721

Bryant, Levi R. The Democracy of Objects. Ann Arbor, MI: Open Humanities Press, 2011.

Colman, Adam. New Uses for Failure: Ben Lerner's 10:04. New York: Fiction Advocate, 2018.

DeLanda, Manuel. Intensive Science and Virtual Philosophy. London, UK: Bloomsbury, 2011.

Deleuze, Gilles, and Félix Guattari. A Thousand Plateaus: Capitalism and Schizophrenia. MN: University of Minnesota Press, 1993. Translation and Forward by Brian Massumi.

Felski, Rita. “Context Stinks!” New Literary History 42, no. 4 (Autumn 2011): 573-91. Fure, Adam. “Aesthetics Postdigital," in Mark Foster Gage (ed.), Aesthetics Equals Politics. The MIT Press, 2019: 99-125.

Gage, Mark Foster (ed.). Aesthetics Equals Politics: New Discourses across Art, Architecture, and Philosophy. Cambridge, MA: The MIT Press, 2019.

Harman, Graham. Guerilla Metaphysics: Phenomenology and the Carpentry of Things. Chicago, IL: Open Court, 2005.

---. Immaterialism: Objects and Social Theory. Cambridge, UK: Polity, 2017.

---. Object-Oriented Ontology: A New Theory of Everything. London, UK: Penguin, 2018.

---. Art and Objects. Cambridge, UK: Polity Press, 2020.

Iovănel, Mihai. “Neocritique: Sherlock Holmes Investigates Literature," Theory in the "Post" Era: A Vocabulary for the Twenty-First-Century Conceptual 
Commons. Ed. Alex Matei, Christian Moraru, and Andrei Terian. New York: Bloomsbury, 2021. Forthcoming.

Latour, Bruno. "An Attempt at a 'Compositionist Manifesto." New Literary History 41, no. 3 (Summer 2010): 471-90.

Lerner, Ben. Leaving the Atocha Station. Minneapolis, MN: Coffee House Press, 2011. ---. 10:04. New York: Picador, 2014.

---. The Hatred of Poetry. New York: Farrar, Straus and Giroux, 2016.

---. The Topeka School. New York: Farrar, Straus and Giroux, 2019.

Meillassoux, Quentin. After Finitude: An Essay on the Necessity of Contingency. London, UK: Bloomsbury, 2016. Translated by Ray Brassier. With a preface by Alain Badiou.

Morton, Timothy. "An Object-Oriented Defense of Poetry." New Literary History 43, no. 2 (Spring 2012): 205-24.

---. "Use the Force," Aesthetics Equals Politics. Ed. Mark Foster Gage. The mIT Press, 2019: 65-79.

Russo, Rhett. "Architecture, Deep and Cryptic." Aesthetics Equals Politics. Ed. Mark Foster Gage. The MIT Press: 269-79.

Shaviro, Steven. Connected, or What It Means to Live in the Network Society. Minneapolis, MN: University of Minnesota Press, 2003.

---. The Universe of Things: On Speculative Realism. Minneapolis, MN: University of Minnesota Press, 2014.

Toth, Josh. Truth and Metafiction: Plasticity and Renewal in American Narrative. New York: Bloomsbury, 2021.

Wisnoski, Barbara. "An Aesthetic of Everything Else: Craft and Flat Ontologies." The Modern Journal of Craft 12, no. 3 (November 2019): 205-17.

Yarbrough, Stephen R. The Levels of Ambience: An Introduction to Integrative Rhetoric. Intermezzo. E-book:

http://intermezzo.enculturation.net/og-yarbrough.htm, 2018. 